\title{
TENSILE STRESS-CRACK WIDTH LAW FOR STEEL FIBRE REINFORCED SELF- COMPACTING CONCRETE OBTAINED FROM INDIRECT (SPLITTING) TENSILE TESTS
}

\author{
Amin Abrishambaf *1, Joaquim A. O. Barros ${ }^{2}$ and Vítor M.C.F. Cunha ${ }^{3}$
}

${ }^{1}$ ISISE, Dep. Civil Eng., School Eng., University of Minho, Campus de Azurém 4800-058 Guimarães, Portugal. e-mail: abrishambaf@ civil.uminho.pt, Tel: +351910860787, Fax: +351253510217.

${ }^{2}$ ISISE, Dep. Civil Eng., School Eng., University of Minho, Campus de Azurém 4800-058 Guimarães, Portugal. e-mail: barros@ civil.uminho.pt, Tel: +351253 510 210, Fax: +351253510217.

${ }^{3}$ ISISE, Eng. Department, School Science and Tech., University of Trás-os-Montes e Alto Douro, 5001-801 Vila Real, Portugal. e-mail: vcunha@utad.pt, Tel: +351259 350 391, Fax: +351 259350356.

\begin{abstract}
In this work, the fracture mode I parameters of steel fibre reinforced self-compacting concrete (SFRSCC) were derived from the numerical simulation of indirect splitting tensile tests. The combined experimental and numerical research allowed a comparison between the stress-crack width $(\sigma-w)$ relationship acquired straightforwardly from direct tensile tests, and the $\sigma-w$ response derived from inverse analysis of the splitting tensile tests results. For this purpose a comprehensive nonlinear 3D finite element (FE) modeling strategy was developed. A comparison between the experimental results obtained from splitting tensile tests and the corresponding FE simulations confirmed the good accuracy of the proposed strategy to derive the $\sigma-w$ for these composites. It is concluded that the post-cracking tensile laws obtained from inverse analysis provided a close relationship with the ones obtained from the experimental uniaxial tensile tests.
\end{abstract}

Keywords: Steel fibre reinforced self-compacting concrete; Splitting tensile test; Uniaxial tensile test; Postcracking strength; Inverse analysis; Fibre orientation. 


\section{INTRODUCTION}

The post-cracking tensile behaviour of random discrete fibre reinforced concrete can be simulated either by a stress-crack width relationship, $\sigma-w$, or a stress-strain relationship, $\sigma-\varepsilon$. In the case of steel fibre reinforced concretes, SFRC, of low fibre content where multiple cracking does not occur, the $\sigma-\varepsilon$ response is usually correlated with the $\sigma-w$ diagram by adopting a characteristic length parameter. The $\sigma-w$ is the most adequate to simulate the post-cracking behaviour of low fibre content SFRC [1], and can be directly obtained from uniaxial tensile tests [2]. On the other hand, in indirect tensile tests, the $\sigma-w$ response of SFRC is assessed by an inverse analysis procedure that takes into account the experimental test results, such as: splitting tensile test [3]; three-point notched beam bending test [4]; wedge splitting test [5]. Fig. 1 depicts the different approaches to estimate the stress - crack width law of SFRC.

It would be expectable that the $\sigma-w$ relationships obtained from different tensile test methods would render close material $\sigma-w$ relationships, but, actually, this does not occur [6]. From a conceptual point of view, the uniaxial tensile test is the most appropriate method to obtain the $\sigma-w$ relationship, since it can provide directly a stress - crack width relationship. From the aforementioned relationship, all the fracture mode I parameters can be derived, namely, the stress at crack initiation, the work of fracture and the shape of the stress - crack width relationship. However, performing this test involves some economic and logistic difficulties, such as the necessity of specialized and expensive equipment, sophisticated test set-up to avoid detrimental interferences, like load eccentricity, since it decreases the stress at the onset of crack initiation [7], therefore, this test is not used so often. Furthermore, the obtained results are quite sensitive to the geometry, size and boundary conditions of the specimens [8-10]. Due to the aforesaid disadvantages, other more simple and economic test methods are being used to determine mode I fracture parameters.

Splitting tensile test, also known as Brazilian test, is well disseminated to estimate the concrete tensile strength. Recently, different types of tests based on the latter have been proposed, namely, double-punch test (Barcelona test) $[11,12]$ and wedge splitting test [13]. The main advantages of the splitting tensile test are that it is quite cheap and simple to be performed on either cylindrical (e.g. extracted cores from real structural elements) or cubic specimens. Moreover, it is only required a testing rig capable of performing compressive loading. Unlike three-point beam bending test, it is expected that the result should be closer to uniaxial tensile test, since most of the bulk concrete along and across the potential fracture plane is subjected to a constant tensile stress [14]. However, beside the transversal tensile stresses, longitudinal compressive stresses also appear. One disadvantage of this test method is that suitable data on the post-cracking regime hardly can be obtained from it 
due to the unstable crack propagation. However, by performing this test with a closed-loop crack width control, a stable response can be achieved, thus this problem can be easily overcome $[15,16]$.

In the case of the three-point beam bending test, Cunha [6] showed that the stress-crack width diagram determined from the inverse analysis of three-point beam bending test results overestimated the tensile postpeak behaviour of steel fibre reinforced self-compacting concrete, SFRSCC, when compared to the one obtained from uniaxial tensile tests. This tendency was also observed, even if the influence of fibre distribution and orientation was taken into consideration. From another point of view, having in mind that concrete's flowability in the fresh state affects significantly fibre orientation / dispersion and, consequently, the mechanical properties of SFRSCC, designing planar structural elements like panels, shells and walls from constitutive laws derived from the results of this test can lead to unrealistic predictions. It has in fact been shown that, when casting beams and panels, fibres tend to be oriented parallel and perpendicular to the concrete flow direction, respectively [17-19]. Therefore, in order to determine a constitutive tensile law that reproduces, as close as possible, the material behaviour in the real structure, recently some design documents such as the Model Code 2010 [20] and the Italian national standard [21] suggest that the testing specimen has to be cast in such a way that its fibre orientation profile is similar to the one in the structural element. Consequently, although bending tests are suggested by recommendations and test standards, such as RILEM 162-TDF and EN-14651[4, 22], researchers prefer to estimate the residual tensile strength of SFRC by means of other methods like uniaxial tensile test, splitting tensile test [23] or centrally loaded round panels as described in ASTM C1550[24]. The present work illustrates a methodology to predict the stress - crack width $(\sigma-w)$ relationship of SFRSCC in thin structural elements using an inverse analysis procedure. For this purpose, splitting tensile tests were performed on extracted cylindrical cores. The $\sigma-w$ relationship of the SFRSCC was obtained from the numerical simulations of the splitting tensile results with a nonlinear 3D finite element model. Finally, the $\sigma-w$ response obtained from inverse analysis was compared to the one directly derived from the uniaxial tensile tests.

\section{RESEARCH SIGNIFICANCE}

The use of steel fibres is becoming a more viable and prevalent option for the reinforcement of concrete structures, mainly those of statically indeterminate nature. Since mechanical behaviour of SFRC is strongly affected by fibre distribution and orientation, a simple methodology to realistically predict the fibre orientation dependent response of fibre reinforced composites in tension is needed. Splitting tensile test could be considered 
for this purpose because it is cheap, does not need sophisticated testing equipment, and can be executed easily also on cores extracted from structural elements, thus maintaining the fibre orientation profile in the same structure. Nevertheless, it is well known that splitting test may not be the most adequate option to ascertain the SFRC tensile parameters, mainly due to the biaxial stress-state at the loading plane. In spite of that, in this work was checked the possibility of employing splitting tensile tests to derive in a realistic fashion the uniaxial tensile stress - crack width relationship.

\section{EXPERIMENTAL PROGRAM AND RESULTS OVERVIEW}

A summary of the experimental program that was carried out by the authors of this research article is presented in this section. More details can be found elsewhere [25].

\subsection{Materials and specimens}

Two steel fibre reinforced self-compacting concrete, SFRSCC, panels were casted from their centre point. The panels measured $1600 \times 1000 \mathrm{~mm}^{2}$ in plan with a $60 \mathrm{~mm}$ thickness. The material constituents, as well as proportions of the designed concrete are represented in Table 1. In the design optimization process of this concrete, the maximum coarse aggregate size was $12 \mathrm{~mm}$. The SFRSCC exhibited a slump flow diameter of 670 $\mathrm{mm}$ in the fresh state. A fibre content of $60 \mathrm{~kg} / \mathrm{m}^{3}$ hooked-end steel fibres was adopted, with a fibre type of a length, $l_{f}$, of $33 \mathrm{~mm}$, diameter, $d_{f}$, of $0.55 \mathrm{~mm}$, aspect ratio, $l_{f} / d_{f}$, of 60 and a yield stress of $1100 \mathrm{MPa}$. The fibre's aspect ratio was selected in order to attend the matrix compressive strength and promote fibre pullout failure mechanism for the optimization of the post-cracking residual tensile strength. At 28 days, the SFRSCC had an average Young's modulus of $34.15 \mathrm{GPa}$, with a coefficient of variation, $\mathrm{CoV}$, of $0.21 \%$, and an average compressive strength of $47.77 \mathrm{MPa}$ with a $\mathrm{CoV}$ of $7.45 \%$.

From each panel, twenty-three cylindrical cores with a diameter of $150 \mathrm{~mm}$ were extracted in various locations, Fig. 2. In this figure the pale dash lines with arrows represent the supposed concrete flow directions. The hatched cores were used for splitting tensile tests, where the remaining ones were used for uniaxial tensile tests. In the splitting tensile specimens, to localize the crack plane, two $5 \mathrm{~mm}$ deep notches were cut on each opposite face of the specimen. To evaluate the influence of the flow driven fibre orientation, by assuming the centre (casting) point as origin, each core was notched in the opposite direction of its symmetric companion, see Fig. 2, where $\theta$ represents the angle between the notched plane and the direction of the concrete flow. 
From the remaining cores extracted from the panels, according to the schematic representation shown in Fig. 3 , twenty two prismatic specimens with dimensions of $110 \times 102 \times 60 \mathrm{~mm}^{3}$ were sawn out for the uniaxial tensile test program. Following the same notching procedure for the splitting test specimens, the prismatic specimens were notched according to parallel $\left(\theta=0^{\circ}\right)$ and perpendicular $\left(\theta=90^{\circ}\right)$ directions to the expected concrete flow. The notch was cut along all the four lateral faces of the specimen, at its mid-height, with a width of $2 \mathrm{~mm}$ and a death of $5 \mathrm{~mm}$.

\subsection{Splitting tensile tests}

In the first phase, the $\sigma-w$ relationship was assessed by performing splitting tensile tests based on the ASTM C-496standard [3]. The tests were performed by closed-loop displacement control, using an external linear variable diferential transducer (LVDT) that was positioned on the actuator to control the vertical deformation of the specimen. The load was applied on the top of the notch. To avoid test instabilities, especially once the crack is initiated in the notched plane (initiation of the softening phase in the response of the specimen), a relatively low displacement rate $(0.001 \mathrm{~mm} / \mathrm{s})$ was employed and kept fixed during the entire test procedure. Five LVDTs were installed on the opposite surfaces of each core to measure crack width along the fracture surface, Fig. 4, three on the front face and two on the rear face of the specimen, which respectively corresponded to the top and bottom faces of the panel mock-up as casted.

\subsection{Uniaxial tensile tests}

Twenty-two prismatic specimens, Fig. 2, were tested to determine the uniaxial tensile $\sigma-w$ relationship following the recommendations of RILEM TDF-162 [2]. To this purpose, two steel loading plates were glued, respectively, to the top and bottom surfaces of the prismatic specimen using Sikadur ${ }^{\circledR}-30$ Normal adhesive. In addition, before starting the tensile test, the specimen was subjected to a uniform pressure for three days to obtain a perfect setting-out of the plates. Afterward, the specimen was removed and bolted to the loading plates of a high stiff universal testing ring. To prevent any rotation of the boundary planes during the test, two stiffeners were fastened on the top and bottom of the specimen, Fig. 5a. Four displacement transducers were installed on the specimens' lateral surfaces corresponding to the top and bottom surface of the panel, as represented in Figs. 5b and 5c. This test was carried under closed-loop displacement control, adopting the following displacement rates during the test: $0.005 \mathrm{~mm} / \mathrm{min}$ up to a displacement of $0.05 \mathrm{~mm}, 0.02 \mathrm{~mm} / \mathrm{min}$ up 
to a displacement of $0.1 \mathrm{~mm}, 0.08 \mathrm{~mm} / \mathrm{min}$ up to a displacement of $0.5 \mathrm{~mm}$, and $0.1 \mathrm{~mm} / \mathrm{min}$ until the completion of the test. The test was controlled by the averaging signal of the four transducers.

\section{NUMERICAL SIMULATION}

In this section, it is presented the methodology for obtaining the post-cracking behaviour of SFRSCC by inverse analysis, IA, of the splitting tensile test results. The experimental applied force - crack width responses were simulated adopting distinct sets of parameters for the tensile stress - crack width law. For this purpose, the ABAQUS $^{\circledR}$ finite element software [26] was used. To check the accuracy of the proposed methodology, further ahead, the $\sigma-w$ relationship obtained from the inverse analysis of the splitting tensile tests will be compared to the $\sigma-w$ directly obtained from the uniaxial tensile test.

The geometry of the specimen and the material behaviour were simulated using an appropriate element and material model available in the ABAQUS ${ }^{\circledR}$ program library $[27,28]$. Due to the symmetry of specimen geometry, supports and loading conditions used in the splitting tensile test setup, a quarter of the specimen was modeled, Fig. 6a. The geometry model comprises two main parts: notch and un-notch (flush) parts since they have different thicknesses. Preliminary analyses were carried out in order to obtain a mesh refinement that does not compromise both the accuracy of the numerical simulations and the computational cost. The assembled mesh parts are depicted in Fig. 6b. In the present mesh, 8-noded solid elements with hexahedral shape and 8integration points were used. The total number of elements was 5674 with the maximum and minimum volumes of $82 \mathrm{~mm}^{3}$ and $39 \mathrm{~mm}^{3}$, respectively. In addition, the distortion of the finite elements was also checked to avoid modeling inaccuracies. To model the softening behaviour of SFRSCC, the numerical analyses were carried out under displacement control method. The non-zero prescribed displacement constraints were applied on the top of the notch part of the model, in similarity to the experiment.

\subsection{Concrete constitutive model}

The concrete damage plasticity (CDP) model was used to simulate the mechanical behaviour of concrete, since it is capable of simulating the damage due to concrete cracking and plastic deformations in compression. In other words, this model uses the concept of isotropic damage elasticity in combination with isotropic compression and tension plasticity to simulate the inelastic behaviour of concrete under compressive and tensile stresses. The model is a modification of the Drucker - Prager hypothesis. 
In general, the flow potential surface and the yield surface make use of the principal stresses $\left(S_{1}, S_{2}, S_{3}\right)$ or the stress invariants $\left(I_{1}, J_{2}, J_{3}\right)$. The yield function defines a surface in the effective stress space in order to represent the states of failure or damage (Fig. 7). The effective stress tensor is determined as follow:

$$
\bar{\sigma}=D_{0}^{e l}:\left(\varepsilon-\varepsilon^{p l}\right)
$$

where $D_{0}^{e l}$ is the initial (undamaged) elastic constitutive tensor of the material, $\varepsilon$ is the strain tensor and $\varepsilon^{p l}$ is the plastic strain tensor. On other hand, the yield function and the flow potential surface use two stress invariants of the effective stress tensor, namely the hydrostatic stress $(\bar{p})$ and the Von Mises equivalent effective stress ( $\bar{q})$ that can be determined from Eqs.(2) and (3), respectively.

$$
\begin{gathered}
\bar{p}=-I_{1} / 3=-1 / 3 \operatorname{trace}(\bar{\sigma}) \\
\bar{q}=\sqrt{3 J_{2}}=\sqrt{3 / 2(\bar{S}: \bar{S})}
\end{gathered}
$$

where $\bar{S}$ is the deviatoric part of the effective stress tensor $\bar{\sigma}$. The potential flow and yield function are defined with four parameters. These parameters are the dilation angle $(\psi)$ and the eccentricity $(e)$ that determines the shape of the potential flow surface, the ratio between the initial biaxial compressive strength and the initial uniaxial compressive strength $\left(\sigma_{b 0} / \sigma_{c 0}\right)$, the $k_{c}$ parameter that defines the initial yield surface and will be detailed subsequently. The potential plastic flow surface in CDP model is the same as Drucker - Prager hyperbolic function:

$$
G=\sqrt{\left(e \sigma_{t 0} \tan \psi\right)^{2}+\bar{q}^{2}}-\bar{p} \tan \psi
$$

Since the potential plastic flow surface is defined in the $p-q$ plane (effective meridional plane), therefore, the dilation angle $(\psi)$ should be measured in the same plane ( $p-q$ plane) at high confining pressure. However, the $\psi$ is simulated as concrete's internal friction angle, which usually ranges between $34^{\circ}$ to $43^{\circ}[29,30]$ depending on the concrete type. According to what is proposed by Jankowiak et al. [31], the eccentricity factor in Eq. (4), $e$, which represents the eccentricity of the potential plastic surface, can be determined by the ratio between the uniaxial tensile strength $\left(\sigma_{t 0}\right)$ and compressive strength $\left(\sigma_{c 0}\right)$.

The CDP model uses a yield surface that is defined as the loading function proposed by Lubliner et al. [32], see Fig. 7. The evaluation of the yield surface is controlled by two hardening variables, namely, the plastic strain in tension $\left(\tilde{\varepsilon}_{t}^{p l}\right)$ and the plastic strain in compression $\left(\tilde{\varepsilon}_{c}^{p l}\right)$. In the case of the effective stress, the yield function is determined as follow: 


$$
F=\frac{1}{1-\alpha}\left(\bar{q}-3 \alpha \bar{p}+\beta\left(\tilde{\varepsilon}^{p l}\right)\left\langle\hat{\bar{\sigma}}_{\max }\right\rangle-\gamma\left\langle\hat{\bar{\sigma}}_{\max }\right\rangle\right)-\bar{\sigma}_{c}\left(\tilde{\varepsilon}_{c}^{p l}\right)
$$

where:

$$
\begin{gathered}
\alpha=\frac{\left(\sigma_{b 0} / \sigma_{c 0}\right)-1}{2\left(\sigma_{b 0} / \sigma_{c 0}\right)-1} \quad, \quad 0 \leq \alpha \leq 0.5 \\
\beta=\frac{\bar{\sigma}_{c}\left(\tilde{\varepsilon}_{c}^{p l}\right)}{\bar{\sigma}_{t}\left(\tilde{\varepsilon}_{t}^{p l}\right)}(1-\alpha)-(1+\alpha) \\
\gamma=\frac{3\left(1-k_{c}\right)}{2 k_{c}-1}
\end{gathered}
$$

In these equations, $\hat{\bar{\sigma}}_{\max }$ stands for the maximum principal effective stress and is the algebraic maximum eigen value of the effective stress $\bar{\sigma}$ indicated in Eq. (1) [33], $\langle x\rangle$ represents Macauley bracket $=1 / 2(|x|+x), \bar{\sigma}_{t}\left(\tilde{\varepsilon}_{t}^{p l}\right)$ and $\bar{\sigma}_{c}\left(\tilde{\varepsilon}_{c}^{p l}\right)$ are the effective tensile and compressive cohesive stresses, respectively, and will be discussed in the subsequent section. Parameter $k_{c}$ is physically assumed as a ratio of the distances between, respectively, the compressive meridian and the tensile meridian with hydrostatic axis in the deviatoric cross section. If this ratio tends to 1 , the deviatoric cross section of the failure surface becomes a circle similar to the Drucker - Prager yielding surface. However, definition of this parameter is only possible if the full triaxial compressive tests are executed on concrete specimens [29]. Table 2 includes the constitutive parameters of CDP model used to simulate the concrete behaviour in the splitting tensile specimens.

\subsubsection{Stress - strain relationship for modeling the SFRSCC uniaxial compressive behaviour}

In CDP model, when the value of the compressive stress $\left(\sigma_{c}\right)$ reaches the compressive strength $\left(\sigma_{c u}=f_{c m}\right)$, the concrete shifts to the softening phase, as depicted in Fig. 8. The compressive inelastic strain, $\tilde{\varepsilon}_{c}^{i n}$, used in CDP model is defined by subtracting the elastic strain component, $\varepsilon_{0 c}^{e l}$, from the total strain, $\varepsilon_{c}$, in the uniaxial compressive test.

$$
\begin{gathered}
\tilde{\varepsilon}_{c}^{i n}=\varepsilon_{c}-\varepsilon_{0 c}^{e l} \\
\varepsilon_{0 c}^{e l}=\sigma_{c} / E_{0}
\end{gathered}
$$


According to what is proposed by CEB-FIP Model Code 2010 [20], in the pre-peak phase concrete starts to show nonlinear behaviour above a stress level corresponding to $40 \%$ of $f_{c m}$. In the CDP model, from the stress - inelastic strain relationship $\left(\sigma_{c}-\widetilde{\varepsilon}_{c}^{i n}\right)$ that is provided by the user, the stress versus strain response $\left(\sigma_{c}-\varepsilon_{c}\right)$ can be converted to the stress - plastic strain curve $\left(\sigma_{c}-\tilde{\varepsilon}_{c}^{p l}\right)$ automatically by the software.

When unloading during the softening stage, the CDP model uses Eq. (11) to convert inelastic strain to plastic strain $\left(\widetilde{\varepsilon}_{c}^{p l}\right)$. In this equation, $d_{c}$, which is known as damage parameter in compression (Fig. 8), depends on the concrete damage level, and ranges from zero to one, respectively for undamaged and fully damage material.

$$
\tilde{\varepsilon}_{c}^{p l}=\tilde{\varepsilon}_{c}^{i n}-\frac{d_{c}}{\left(1-d_{c}\right)} \frac{\sigma_{c}}{E_{0}}
$$

By assuming $E_{0}$ as the concrete initial modulus of elasticity in the undamaged phase, it can be determined the compressive stress and also the effective cohesive stress by Eqs. (12) and (13).

$$
\begin{gathered}
\sigma_{c}=\left(1-d_{c}\right) E_{0}\left(\varepsilon_{c}-\tilde{\varepsilon}_{c}^{p l}\right) \\
\bar{\sigma}_{c}=\sigma_{c} /\left(1-d_{c}\right)=E_{0}\left(\varepsilon_{c}-\tilde{\varepsilon}_{c}^{p l}\right)
\end{gathered}
$$

Available research $[34,35]$ shows that the post-peak behaviour of fibre reinforced composites, FRC, in compression cannot be simulated by the models proposed for plain concrete [36], due to the higher post-peak compressive residual strength provided by fibre reinforcement. Therefore, among some available expressions in literature for FRC [37-40], the model proposed by Barros and Figueiras [40] was used to derive the stress inelastic strain relationship $\left(\sigma_{c}-\widetilde{\varepsilon}_{c}^{i n}\right)$ for SFRSCC. This relationship was defined and input into the software taking into account the compressive strength from the experimental part (section 3.1). This relationship is dependent on two parameters, namely, the compressive strength, $f_{c m}$, and the fibre weight percentage, $W_{f}$ and is determined by:

$$
\sigma_{c}=f_{c m} \frac{\varepsilon_{c} / \varepsilon_{c 1}}{(1-p-q)+q\left(\varepsilon_{c} / \varepsilon_{c 1}\right)+p\left(\varepsilon_{c} / \varepsilon_{c 1}\right)^{(1-q) / p}}
$$

with

$$
\left.q=1-p-E_{c 1} / E_{c i}, \quad p+q \in\right] 0,1\left[, \quad \frac{1-q}{p}>0\right.
$$

and 


$$
p=1.0-0.919 \exp \left(-0.394 W_{f}\right)
$$

In eq. (14), $\varepsilon_{c 1}$ is the strain at compressive strength, and for concretes reinforced with hooked-end steel fibres of an aspect ratio of 60 (the ones used in the present experimental programs) is given by:

$$
\varepsilon_{c 1}=\varepsilon_{c 10}+0.0002 W_{f}
$$

According to CEB-FIP Model Code 2010 [20], $\varepsilon_{c 10}$, which is the strain at compressive strength of plain concrete, is equal to $2.2 \times 10^{-3}, E_{c i}$ is the tangent modulus of elasticity, obtained from $21500\left[f_{c m} / 10\right]^{1 / 3}$, and $E_{c 1}$ is the secant modulus of elasticity given by $f_{c m} / \varepsilon_{c 1}$. From the aforementioned equations, the compressive mechanical properties and the stress - strain relationship used in the numerical simulation were determined. Table 3 includes the values of the model parameters used for the compressive behaviour.

\subsubsection{Stress - strain relationship for modeling the SFRSCC uniaxial tensile behaviour}

The stress - strain response under uniaxial tension follows a linear elastic behaviour until it reaches the tensile strength $\left(\sigma_{t 0}\right)$, which corresponds to the coalescence of micro-cracking into a macro-crack. Once the tensile strength is attained, the stress starts to decrease, Fig. 9. If strain softening of SFRC is considered, the stress reduction is controlled by the reinforcement mechanisms of fibres bridging the active crack plane. The SFRC softening phase is expressed as a function of cracking strain, $\tilde{\varepsilon}_{t}^{c k}$, which can be determined by subtracting the elastic strain corresponding to the undamaged part from the total strain:

$$
\begin{gathered}
\tilde{\varepsilon}_{t}^{c k}=\varepsilon_{t}-\varepsilon_{0 t}^{e l} \\
\varepsilon_{0 t}^{e l}=\sigma_{t} / E_{0}
\end{gathered}
$$

From the stress versus cracking strain response $\left(\sigma_{t}-\widetilde{\varepsilon}_{t}^{c k}\right)$ defined by the user, the stress - strain curve ( $\left.\sigma_{t}-\varepsilon_{t}\right)$ is converted to stress - plastic strain relationship $\left(\sigma_{t}-\tilde{\varepsilon}_{t}^{p l}\right)$. In case of an unloading phase, the effective plastic tensile strain, $\tilde{\varepsilon}_{t}^{p l}$, stress, $\sigma_{t}$, as well as the effective cohesive tensile stress, $\bar{\sigma}_{t}$, are derived using an approach similar to the one adopted for the compressive behaviour, as detailed in section 4.1.1.

In order to assure that results are not dependent on the refinement of the finite element mesh, it is preferable to implement fracture energy cracking criterion to define tension stiffening of concrete. In this case, the concrete tensile response is modeled by a stress - crack width displacement curve $\left(\sigma_{t}-w\right)$ rather than stress - strain 
relationship $\left(\sigma_{t}-\varepsilon_{t}\right)$. However, implementation of this concept requires the adoption of a characteristic length parameter $(L)$ associated to an integration point. This parameter depends on the element geometry, dimensions of the element and of the adopted integration scheme [28].

\subsection{Inverse analysis procedure}

The values $\sigma_{i}$ and $w_{i}$ that define the tensile stress - crack width law were determined by fitting the numerical load - crack width curve to the correspondent experimental average curve. The applied inverse analysis methodology followed up what was proposed by Roelfstra and Wittmann [41]. This procedure can be divided into three main steps. In the first stage, a preliminary set of the parameters that define the $\sigma-w$ relationship were initialized and set as input of the uniaxial tensile behaviour in the model (section 4.1.2), and the error of the numerical simulation was also initialized $\left(e r r_{f}=5 \%\right)$. In the second stage, the numerical load - crack width response, $F_{N U M}-w$, was obtained from the nonlinear finite element analysis. In the last step, the computed numerical $F_{N U M}-w$ response was compared to the experimental one, $F_{E X P}-w$. The value of the force at distinct crack widths were computed, and the normalized error, err, was determined as follows:

$$
e r r=\sum_{i=0}^{w_{u}}\left|F_{i E X P}-F_{i N U M}\right| / \sum_{i=0}^{w_{u}} F_{i E X P}
$$

where $F_{i E X P}$ and $F_{i N U M}$ were the experimental and the numerical load value at $i$ crack width value, respectively. The final SFRSCC $\sigma-w$ relationship was defined by the parameter set that leads to a lowest normalised error between the experimental and numerical compressive force versus crack width curves.

\subsection{Numerical results, validation and discussion}

Fig. 10 depicts the experimental compressive force - crack width curves obtained from the splitting tensile tests, when the notch plane is parallel $\left(\theta=0^{\circ}\right)$ and perpendicular $\left(\theta=90^{\circ}\right)$ to the concrete flow direction. The plotted crack width was calculated as the average of the values measured by the five LVDTs. In this figure,

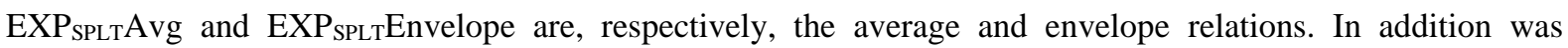
comprised the numerical response $\left(\mathrm{NUM}_{\mathrm{SPLT}}\right)$ obtained from inverse analysis. The numerical analysis was carried out up to a crack width of $2 \mathrm{~mm}$ measured at the centre height of the cylinder. A good accuracy between the numerical and experimental responses was observed up to this crack width limit. Table 4 includes the 
residual numerical and experimental forces and the normalized fitting error (err) obtained by Eq. (20). In this table, $F_{c r}$ and $F_{p e a k}$ are forces at crack initiation and peak load, respectively; $F_{0.3}, F_{1}$ and $F_{2}$ are the post-cracking residual forces at a crack width of $0.3,1$ and $2 \mathrm{~mm}$, respectively. When analyzing the abovementioned residual forces, a negligible difference between the numerical and experimental results was observed. If one compares the determined error (err) for each series, they were smaller than the initialized error $(5 \%)$.

Fig. 11 presents the obtained $\sigma-w$ from the inverse analysis of the splitting tensile tests, according to the strategy explained in section 4.2. The numerical tensile strengths were 3.6 and $3.2 \mathrm{MPa}$ for $\theta=0^{\circ}$ and $\theta=90^{\circ}$ specimens, respectively. However, the post-cracking residual stresses in the case of the $\theta=0^{0}$ series were considerable higher. This was due to the fibres tendency to be oriented perpendicular to the concrete flow direction, when panels are casted from the centre. As shown in Fig. 12, there is a higher probability of more fibres intersecting the fracture surface in specimens with a notch plane coinciding with the concrete flow lines, $\left(\theta=0^{0}\right.$, Fig. 2), than in the $\theta=90^{\circ}$ series. This was also supported on the counted number of fibres at the fracture surface, details regarding this aspect can be found elsewhere [25].

Figs.13a-e depict the strains at various loading phases for the numerical modeling of the $\theta=90^{0}$ series. Fig. 13a shows the strain distribution just before the crack formation (pre-cracking stage). In this stage, the tensile strain field mainly raised at mid height of the notch's region. Up to this strain level, the strains were due to the transversal elastic deformation of the SFRSCC bulk. Once the concrete tensile stress was reached, which coincided with attaining the peak load, a crack started to format the specimens' mid height opposite notch tips spreading upward and to the centre as illustrated in Fig. 13b. In the latter figure, the strain value was converted from the elastic strain to the cracking strain $\left(\varepsilon_{c r}\right)$. As it was expected, the crack localization happened at the mid height of the notch part. After this step, the material showed a softening response and the crack progressed from the opposite notch tips to the center of the specimen and towards the loading supports, see Figs. $13 \mathrm{c}$ and $13 \mathrm{~d}$. Finally, this stage was followed by the crack widening at the centre of the specimen (see the deformed mesh in the Fig.13e) and decrease of the load bearing capacity of the specimen.

\section{UNIAXIAL TENSILE RESPONSE VS. TENSILE LAW OBTAINED FROM IA}

Figs. 14 and 15 depict for the $\theta=0^{\circ}$ and $\theta=90^{\circ}$ series, respectively, the uniaxial $\sigma-w$ relationships obtained from the inverse analysis procedure of the splitting tensile test $\left(N U M_{S P L T}\right)$, the envelope and average curves from uniaxial tensile test $\left(\mathrm{EXP}_{\mathrm{UTT}}\right.$ Envelope, EXP $\mathrm{UtT}_{\mathrm{T}}$ Avg.) carried out according to the RILEM TDF-162 


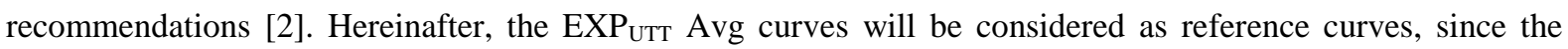
uniaxial tensile test is the only test that could render the accurate tensile stress - crack width relationship. Consequently, they will be used for the validation of the presented numerical methodology. Additionally is presented the $\sigma-w$ relation with the stress calculated according to Eq. (21) as proposed by ASTM C-496 standard $\left(\mathrm{EXP}_{\mathrm{SPLT}}\right)[3]$ :

$$
\sigma_{S P L T}=\frac{2 F}{\pi l d}
$$

where $F$ is the applied line load, $d$ is the diameter of the cylinder $(150 \mathrm{~mm})$ and $l$ is the thickness of the net area in the notched plane $(50 \mathrm{~mm})$.

The $\sigma-w$ relationship obtained from the inverse analysis procedure rendered a relatively good approximation of the uniaxial tensile response, principally, for the series $\theta=90^{\circ}$. As it was represented in Fig. 14, $N U M_{S P L T}$ and EXP $P_{S P L T}$ approaches rendered similar tensile strengths, 3.6 and 3.3 $\mathrm{MPa}$, respectively, which were higher than EXP $_{\text {UtT }}$ Avg. This was expectable, since according to the literature, splitting tensile tests slightly overestimated the tensile strength when comparing to the uniaxial tensile test. The obtained tensile strength from the $N U M_{S P L T}$ (3.6MPa) was in accordance with the mean value suggested by CEB-FIP Model Code 2010 [20] (3.5MPa). At the early cracking stages $(\mathrm{w}<0.6 \mathrm{~mm}) N U M_{S P L T}$ and $E X P_{S P L T}$ approaches gave a stress - crack width relationship nearby the upper bound limit of the EXP $P_{\mathrm{UTT}}$ Envelope. However, this overestimation could be ascribed to the effects of the compressive stress along the notch plane. Figs. 16a to Fig. 16e depict the stress field in the case of the $\theta=0^{\circ}$ simulation accordingly to the horizontal (S11) and vertical (S22) directions: on the cracking onset; at $w=0.5 \mathrm{~mm}$ corresponding to the maximum tensile stress, see Fig. 11 ; at $w=1 \mathrm{~mm}$ within the softening phase. Figs. 16a and Fig. 16b show that once the stress in the S11direction reached the tensile strength of the material, all the elements at the notch zone were subjected to compressive stresses in the S22 direction. Therefore, this biaxial stress state led to an overestimation of the tensile strength in the splitting tests. After the cracking initiation, up to a crack width of $0.5 \mathrm{~mm}$, the tensile stresses in S11direction reached its maximum value, while in the S22 direction the compressive stress level decreased in the notch plane by appearing another area under compression contiguous to the specimen's notch region. Therefore, due to the applied compressive load and the consequent biaxial stress state installed up to the $\mathrm{w}=0.5 \mathrm{~mm}$, many elements were confined and $\sigma$ $-w$ relationship derived from the inverse analysis was somehow overestimated. From another point of view, in the inverse analysis procedure for both series, the stress-strain response in compression was derived using a model proposed by Barros and Figueiras [40] with an assumption that the fibres were distributed and oriented 
randomly. It is shown that in the case of FRC the compressive post-peak response depends on the contribution of the fibres to bridge cracks. In reality, the compressive behaviour of $\theta=0^{\circ}$ specimen could render a higher post-peak response due to the greater number of the fibres and their preferential orientation towards the direction of the applied stress.

Once the crack gets wider, $E X P_{S P L T}$ method is unable to correctly predict the tensile behaviour, since this method assumes a linear elastic stress distribution. On the other hand, $N U M_{S P L T}$ starts to get closer to the response obtained from the uniaxial tensile test. This trend could be justified by analysis of Figs $16 \mathrm{e}$ and $16 \mathrm{f}$. In these figures, all the elements in the central zone of the notch plane were subjected to the tensile stress in the both directions since the compressive stress area along the fracture plane was decreased and shifted. The accuracy of these methods for predicting the experimental $\sigma-w$ curves was also quantified by its fracture parameters. Table 5 includes the residual stresses and toughness parameters for different average crack widths obtained from distinct methods. In this table, $\sigma_{\text {peak }}$ is the stress at peak load; $\sigma_{0.3}, \sigma_{1}$ and $\sigma_{2}$ are the residual stresses at a crack width of $0.3,1$ and $2 \mathrm{~mm}$, respectively; $G_{F 1}$ and $G_{F 2}$ are the dissipated energy up to a crack width of, respectively, 1 and $2 \mathrm{~mm}$. By comparing the determined fracture parameters for the $N U M_{S P L T}$ and $E X P_{S P L T}$ relations, regarding the $\theta=0^{\circ}$ series, they showed higher values than the EXPUTTAvg, respectively, $13 \%, 66 \%$ in the case of $\sigma_{1}, 9.65 \%, 144.74 \%$ for $\sigma_{2}$ and $42 \%, 64 \%$ in $G_{F 2}$.

Regarding the tensile strength in $\theta=90^{\circ}$ series (see Fig. 15), like the previous series, inverse analysis procedure of the splitting tensile tests overestimated it when comparing to the tensile strength obtained from the uniaxial tests, although it was within the experimental envelope. According to the $E X P_{\text {UTT }}$ results, abrupt load decay occurred at crack initiation due to the brittle nature of concrete fracture and lower fibre content. The loss of stress is interrupted when hooked fibre reinforcement mechanisms become more effective, which happens at a crack width in-between [0.1 - 0.3] mm [6] and pseudo-hardening phase is initiated. The result of the inverse analysis method reproduced the $E X P_{\mathrm{UTT}}$ response with an acceptable accuracy, because in this series, during all steps a major number of the elements in the fracture plane were subjected to tensile stress in both directions. Since the tensile residual stresses of this series were much lower than the previous series $\left(\theta=0^{\circ}\right)$, the load bearing capacity of the specimen was decreased and the compressive stresses were not so preponderant in the overall response.

The experimental splitting $\sigma-w$ method, EXP $P_{S P L T}$, clearly overestimated the post-cracking behaviour for the same reasons pointed out previously for the $\theta=0^{\circ}$ series. These differences become more visible if one compares the fracture parameters included in Table 5. This comparison could be performed by estimating an error for each 
parameter separately. Hence, for $N U M_{S P L T}$ and $E X P_{S P L T}$ methods, regarding the $\theta=90^{\circ}$ series, they both showed a higher value than $\operatorname{EXP}_{U T T} \mathrm{Avg}$, respectively, of $0.95 \%, 102 \%$ in the case of $\sigma_{0.3} ; 37 \%, 92 \%$ for $\sigma_{1} ; 15 \%, 91$ $\%$ in $G_{F 1}$ and finally $17 \%, 106 \%$ in the case of $G_{\mathrm{F} 2}$.

Fig. 17 depicts the relationships between the ratio of the splitting tensile post-cracking parameters obtained from inverse analysis procedure, $\sigma_{\mathrm{SPLT}}$ and $G_{F}$ SPLT , and the uniaxial tensile post-cracking parameters, $\sigma_{\mathrm{UTT}}$ and $G_{F ~ U T T}$, respectively, for distinct crack widths. The data plotted in Fig. 17 clearly showed that $\sigma_{\text {SPLT }}$ was generally higher than $\sigma_{\text {UTT }}$ for almost all $w(C M O D)$ values. Therefore, the inverse analysis of the splitting tensile test overestimated the tensile residual strength, being this effect more preponderant on the specimens with more effective fibres at the crack surface. In spite of that, it should be noticed that in most cases the residual parameters, which define the $\sigma-w$ law, were within the experimental envelope of the uniaxial tensile tests, see Figs. 14 and 15. The overall results were predominantly satisfactory if considering the anisotropic material behaviour due to the anisometry of the fibre orientation and distribution induced by the flowability of concrete.

\section{CONCLUSION}

In the present work the uniaxial tensile behaviour of steel fibre reinforced self-compacting concrete was obtained indirectly by performing inverse analysis on the experimental results of splitting tensile tests. To validate the presented methodology, the obtained tensile stress versus crack width relationship $(\sigma-w)$ was then compared to the one directly obtained from the uniaxial tensile test. For this purpose, a comprehensive nonlinear 3D finite element model was used to simulate the splitting tensile tests.

The application of the inverse analysis procedure of the splitting tensile test's experimental results predicted successfully the tensile post-cracking parameters of SFRSCC. On the other hand, the prediction of the fracture parameters directly from the experimental behaviour of the splitting tests, $E X P_{S P L T}$, i.e. assuming a linear stress distribution at the notch section, as expected, rendered not so good results. The $\sigma-w$ responses determined by the inverse analysis technique reproduced all the distinct phases observed during the uniaxial tensile test, particularly, the reduction in the strength due to the loss of the matrix's stiffness once the crack initiated and also the semi-hardening phase at the early cracking stages. Considering the obtained tensile strength from the three mentioned methods, $N U M_{S P L T}$ and $E X P_{S P L T}$ tend to overestimate the tensile strength obtained from uniaxial tensile tests, EXP $P_{U T T}$. However, the determined tensile strength by inverse analysis, $N U M_{S P L T}$, is reasonably in accordance with the suggested by CEB-FIP Model Code 2010 [20]. 
The predicted post-cracking response from inverse analysis of splitting tensile test tends to slightly overestimate the response acquired from the uniaxial tensile tests. However, this can be diluted by the scatter of SFRSCC composites, due to the dispersion and orientation of the fibres. Moreover, one has to account with the distinct nature of the two testing methods, which will induce completely distinct stress states at the fracture surface. In the uniaxial tensile tests, the concrete in the fracture plane is subjected to the pure tensile stress, while in the splitting tensile test a high compressive stress regionarises near the supports will dissipate some energy. In general, in the case of using high fibre content in FRC, especially when the tensile behaviour shows a partial or complete hardening behaviour, the presented methodology could somehow overestimate the constitutive $\sigma-w$ response. Therefore in this case it is preferable to execute another indirect tensile test configuration, by e.g. the one proposed by di Prisco et al. [42].

In conclusion, the overall results are predominantly satisfactory if considering the distinct nature of the tests and of the SFRSCC anisometry. The inverse analysis of the splitting tensile response can predict with a relatively good accuracy the uniaxial tensile post-cracking behaviour, in particular, for low fibre contents.

\section{AKNOWLEDEGMENT}

The studies reported in this paper are part of the research project LEGOUSE (QREN, project $\mathrm{n}^{\circ}$ 5387). This project is co-supported by FEDER through COMPETE program ("Programa Operacional Factores de Competitividade"). The materials were supplied by Radmix and Maccaferri (fibres), SECIL (cement), SIKA and BASF (superplasticizers), Omya Comital (limestone filler), and Pegop (Fly ash).

\section{REFERENCES}

[1] Montaignac R, Massicotte B, CharronJP, NourA. Design of SFRC structural elements: post-cracking tensile strength measurement. Mater Struct 2011;45: 609-622.

[2] RILEM TC162-TDF, Test and design methods for steel fibre reinforced concrete: Uniaxial tension test for steel fibre reinforced concrete. Mater Struct 2001;34: 3-6.

[3] ASTM C496, Standard test method for splitting tensile strength of cylindrical concrete specimens, Annual Book of ASTM Standards: American Society of Testing Materials, 2004. 
[4] RILEM TC162-TDF, Test and design methods for steel fibre reinforced concrete: Bending test. Mater Struct $2000 ; 33: 75-81$

[5] Skocek J, Stang H. Inverse analysis of the wedge-splitting test. Eng Fract Mech 2008;75: 3173-3188.

[6] Cunha VMCF. Steel Fiber Reinforced Self-Compacting Concrete (from Micro-Mechanics to Composite Behaviour). PhD Thesis. Portugal, University of Minho, 2010.

[7] Zhou FP. Some aspects of tensile fracture behaviour and structural response of cementicious materials. Report no. tvbm-1008, division of building materials, Lund Institute of Technology, Lund, Sweden, 1988.

[8] Bazant ZP, Pfeiffer PA. Determination of fracture energy from size effect and brittleness number. Cem Concr Compos 1987;84:463-480.

[9] Carpinteri A, Chiaia B, Cornetti P. A scale-invariant cohesive crack model for quasi-brittle materials. Eng Fract Mech 2002;69: 207-217.

[10] Barragan BE. Failure and Toughness of Steel Fiber Reinforced Concrete under Tension and Shear. PhD thesis. Barcelona, Spain, Universitat Politecnica de Catalunya, 2002.

[11] Molins C, Aguado A, Saludes S. Double punch test to control the tensile properties of FRC (Barcelona Test), Mater Struct 2009;42:415-425.

[12] Chen W. Double punch test for tensile strength of concrete. ACI Mater J 1970;67:993-995.

[13] Ostergaard L. Early-age fracture mechanics and cracking of concrete. PhD thesis. Denmark, Technical University of Denmark, 2003.

[14] Carmona S, Aguado A. New model for the indirect determination of the tensile stress-strain curve of concrete by means of the Brazilian test. Mater Struct 2012;45: 1473-1485.

[15] Carmona S, Gettu R, Aguado A. Study of the post-peak behaviour of concrete in the splitting-tension test, fracture mechanism of concrete structures. In: H. Mihashi, K. Rokugo. Proceedings of Third International Congress. Gifu, Japan, 1998. p.111-120.

[16] Rocco C, Guinea G, Planas J, Elices M. Mechanism of rupture in splitting tests. ACI Mater J 1999;96:5260.

[17] Ferrara L, Meda A. Relationships between fibre distribution, workability and the mechanical properties of SFRC applied to precast roof elements. Mater Struct 2006;39:411-420.

[18] Pansuk W, Sato H, Sato Y, Shionaga R. Tensile behaviours and fibre orientation of UHPC. Proceedings of Second International Symposium on Ultra High Performance Concrete: Kassel, Germany (Kassel University Press), 2008. p.161-168. 
[19] Kim SW, Kang ST, Park JJ, Ryu GS. Effect of filling method on fibre orientation and dispersion and mechanical properties of UHPC. Proceedings of Second International Symposium on Ultra High Performance Concrete: Kassel, Germany (Kassel University Press), 2008. p.185-192.

[20] CEB-FIP Model Code 2010 - Volume 1. Tomas Telford, Lausanne, Switzerland, 2012.

[21] UNI 11039, Steel fibre reinforced concrete - Part I: Definitions, classification, specification and conformity - Part II: test method for measuring first crack strength and ductility indexes. Italian Board for Standardization, 2003.

[22] EN 14651. Test method for metallic fibered concrete - Measuring the flexural tensile strength (limit of proportionality (LOP), residual). European Committee for Standardization, Brussels, 2005.

[23] Laranjeira F, Grunewald S, Walraven J, Blom C, Molins C, AguadoA. Characterization of the orientation profile of steel fiber reinforced concrete. Mater Struct 2010;14:1093-1111.

[24] ASTM C1550. Standard test method for flexural toughness of fibre reinforced concrete (using centrally loaded round panel), Annual Book of ASTM Standards. American Society of Testing Materials, 2004.

[25] Abrishambaf A, Barros JAO, Cunha VMCF, Cunha FNM. Assessment of fibre orientation and distribution in steel fibre reinforced self-compacting concrete panels. $8^{\text {th }}$ RILEM International Symposium on Fibre Reinforced Concrete: Challenges and Opportunities (BEFIB), 2012.

[26] Abaqus Unified FEA software: User Manual. Dassault Systèmes Simulia Corp., Providence, RI, USA, 2009.

[27] Abaqus Unified FEA software: Analysis user's manual, Volume IV: Elements. Dassault Systèmes Simulia Corp., Providence, RI, USA, 2009.

[28] Abaqus Unified FEA software: Analysis user's manual, Volume III: Materials. Dassault Systèmes Simulia Corp., Providence, RI, USA, 2009.

[29] Kmiecik P, Kaminski M. Modeling of reinforced concrete structures and composite structures with concrete strength degradation taken into consideration. Arch Civ Mech Eng 2011;11:623-636.

[30] Lee HJ, Kuchma DA, Baker W, Novak LC. Design and analysis of heavily loaded reinforced concrete link beams for Burj Dubai. ACI Struct J 2008;105:451-459.

[31] Jankowiak I, Kakol W, Madaj A. Identification of a continuous composite beam numerical model, based on experimental tests. $7^{\text {th }}$ Conference on Composite Structures: Zielona Gora, 2005. p. 163-178.

[32] Lubliner J, Oliver J, Oller S, Onate E. A plastic-damage model for concrete. Int J Solid Struct 1989;25:299329. 
[33] Jankowiak T, Lodygowski T. Identification of parameters of concrete damage plasticity constitutive model. Found Civ Environ Eng 2005;6.

[34] Balaguru PN, Sham SP. Fibre reinforced cement composites. Civil Engineering Series, Mc Graw-Hill International Editions, 1992.

[35] Barros JAO. Behaviour of fibre reinforced concrete: experimental research and numerical simulation. $\mathrm{PhD}$ thesis. Portugal, University of Porto, 1995.

[36] Wee TH, Chin MS, Mansur MA. Stress-strain relationship of high-strength concrete in compression. ASCE J Mater Civ Eng 1996;8:70-76.

[37] Cunha VMCF, Barros JAO, Sena-Cruz JM. Modeling the influence of age of steel fibre reinforced self compacting concrete on its compressive behaviour. Mater Struct 2008;41:465-478.

[38] Fanella DA, Naaman A. Stress-strain properties of fiber reinforced mortar in compression. ACI J $1985 ; 82: 475-483$.

[39] Ezeldin AS, Balaguru PN. Normal- and high-strength fiber-reinforced concrete under compression. ASCE J Mater Civ Eng 1992;4:415-429.

[40] Barros JAO, Figueiras JA. Flexural behaviour of SFRC: Testing and modeling. ASCE J Mat Civ Eng $1999 ; 11: 331-339$.

[41] Roelfstra PE, Wittmann FH. Numerical method to link strain softening with failure of concrete. In: FH Wittmann, editor. Fract Toughness and Fract Eng: London, 1986. p. 163-175.

[42] di Prisco M, Ferrara L, Lamperti MGL. Double edge wedge splitting (DEWS): an indirect tension test to identify post-cracking behaviour of fibre reinforced cementitious composites. Mater Struct 2013; 46:1893-1918. 


\section{FIGURES AND TABLES}

\section{List of Figures:}

Fig.1 - Scheme of distinct approaches to estimate the stress - crack width law of SFRC.

Fig. 2 - Core extracting plan: (a) panel A, (b) panel B (hatched specimens for splitting tensile tests; remaining specimen for uniaxial tensile tests).

Fig. 3 - Schematic representation of the prismatic specimen production from an extracted core (dimensions are in $\mathrm{mm})$.

Fig. 4 - Geometry of the specimen and setup of the splitting tensile test (dimensions are in $\mathrm{mm}$ ): (a) specimen front view (top of the panel), (b) specimen lateral view and (c) LVDT connection detail.

Fig. 5 - Uniaxial tensile test setup: (a) specimen front view, (b) specimen lateral view, (c) LVDT connection detail.

Fig. 6 - Three - dimensional view of numerical model: (a) Geometry, constraints and prescribed displacement, (b) Finite element mesh.

Fig. 7 - Yield surface under biaxial stress used in the concrete damage plasticity model.

Fig. 8 - Definition of inelastic compressive strain in the CDP model.

Fig. 9 - Strain definition after cracking-tension stiffening.

Fig. 10 - Experimental and numerical force - crack width relationship, $F$ - $w$, for: (a) $\theta=0^{\circ}$ and (b) $\theta=90^{\circ}$.

Fig. 11 - Numerical stress - crack width relationship, $\sigma-w$, for: (a) $\theta=0^{\circ}$ and (b) $\theta=90^{\circ}$.

Fig. 12 - Explanation for fibre alignment in flowing concrete of a panel casting from the centre.

Fig. 13 - Strain distribution in numerical model.

Fig. 14 - Comparison of the stress - crack width relationship, $\sigma-w$, for $\theta=0^{\circ}$.

Fig. 15 - Comparison of the stress - crack width relationship, $\sigma-w$, for $\theta=90^{\circ}$.

Fig. 16 - Stress distribution in numerical modeling of $\theta=0^{\circ}$ specimen: (a) horizontal direction at the time of the crack initiation, (b) vertical direction at the time of the crack initiation, (c) horizontal direction and $w=0.5 \mathrm{~mm}$, (d) vertical direction and $w=0.5 \mathrm{~mm}$, (e) horizontal direction and $w=1 \mathrm{~mm}$, (f) vertical direction and $w=1$ $\mathrm{mm}$.

Fig. 17 - Numerical splitting tensile post cracking parameters versus experimental uniaxial tensile post-cracking parameters: (a) Residual stress and (b) Fracture energy. 


\section{List of Tables:}

Table 1 - Mix proportions of steel fibre reinforced self-compacting concrete per $\mathrm{m}^{3}$.

Table 2 - The constitutive parameters of CDP model.

Table 3 - Mechanical properties applied in numerical simulation.

Table 4 - Comparison of the FE analysis and experimental results.

Table 5 - Residual stress and toughness parameters obtained from different analysis. 


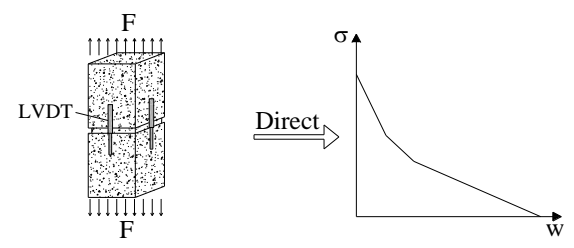

$\underline{\underline{\text { Uniaxial tensile test }}}$

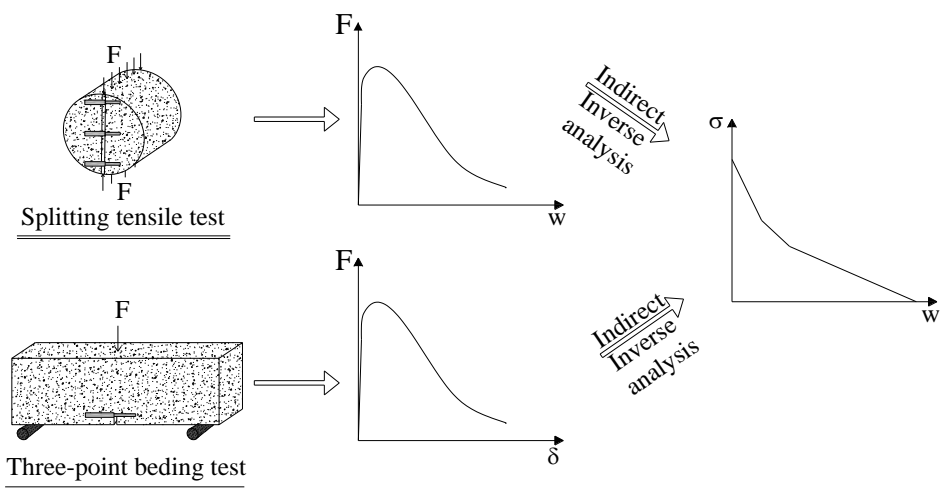

Fig.1 - Scheme of distinct approaches to estimate the stress - crack width law of SFRC. 


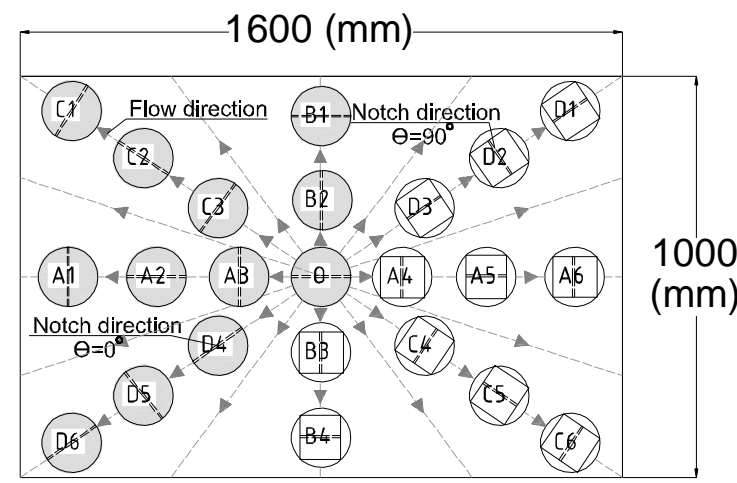

(a)

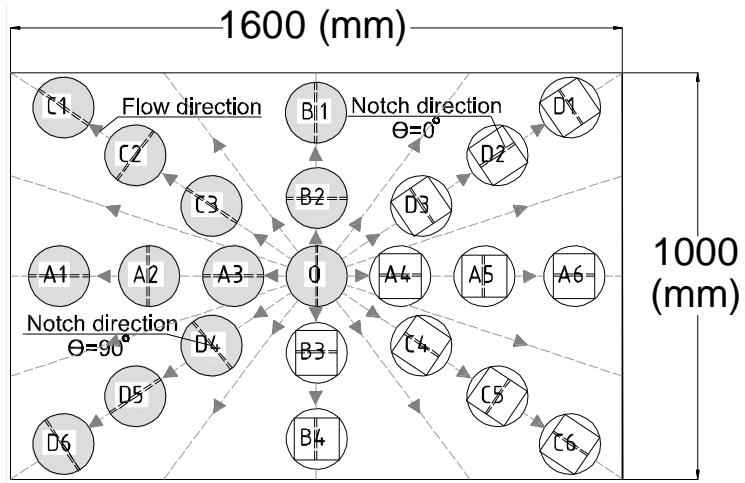

(b)

Fig. 2 - Core extracting plan: (a) panel A, (b) panel B (hatched specimens for splitting tensile tests; remaining specimen for uniaxial tensile tests). 

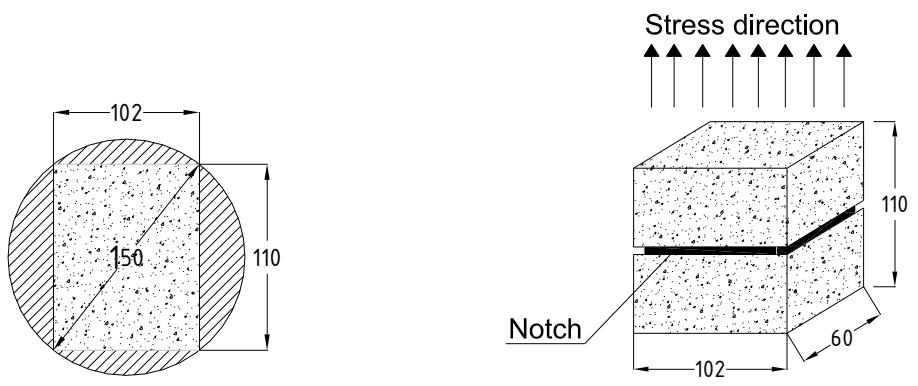

Fig. 3 - Schematic representation of the prismatic specimen production from an extracted core (dimensions are in $\mathrm{mm})$. 


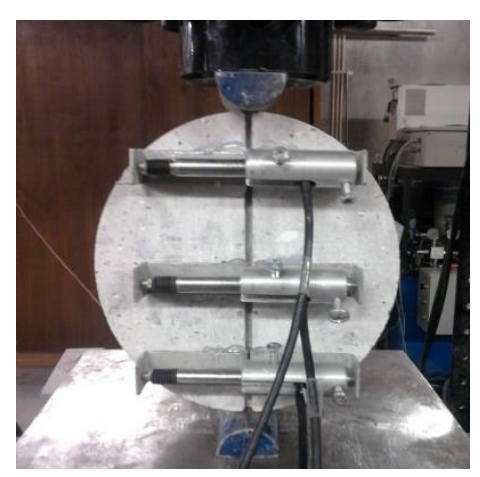

(a)

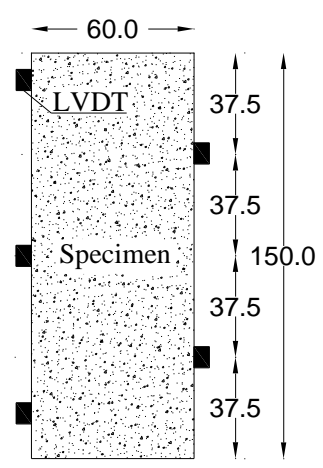

(b)

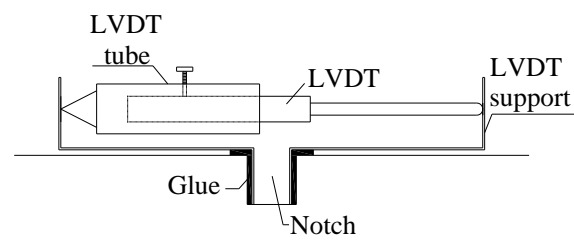

(c)

Fig. 4 - Geometry of the specimen and setup of the splitting tensile test (dimensions are in $\mathrm{mm}$ ): (a) specimen front view (top of the panel), (b) specimen lateral view and (c) LVDT connection detail. 


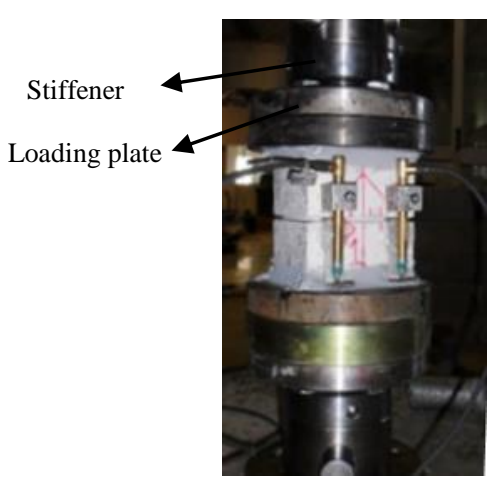

(a)

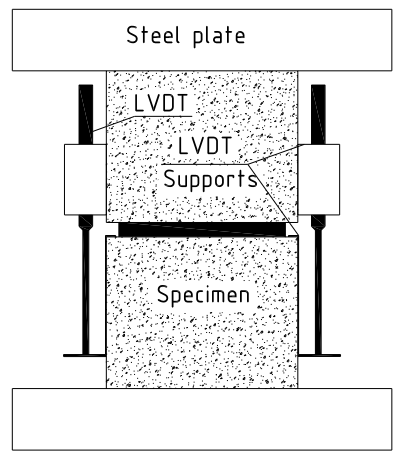

(b)

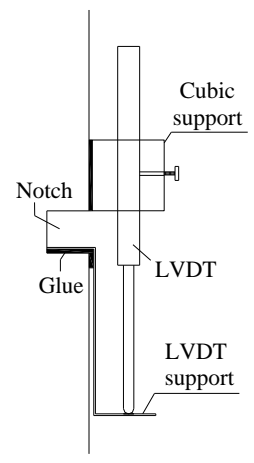

(c)

Fig. 5 - Uniaxial tensile test setup: (a) specimen front view, (b) specimen lateral view, (c) LVDT connection detail. 


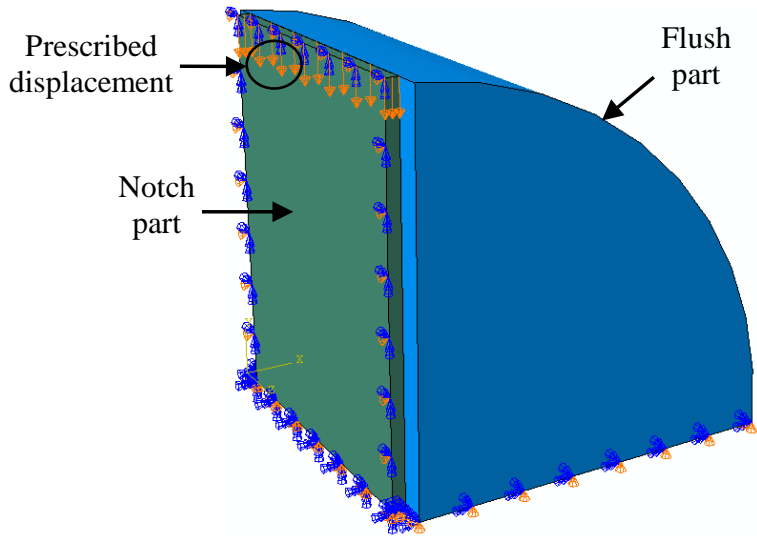

(a)

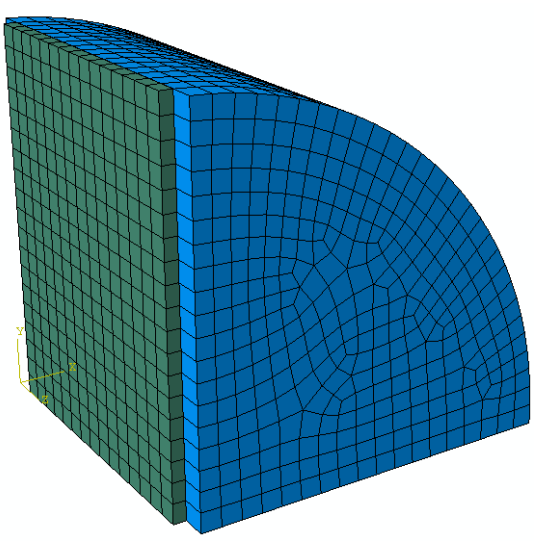

(b)

Fig. 6 - Three-dimensional view of numerical model: (a) Geometry, constraints and prescribed displacement, (b) Finite element mesh. 


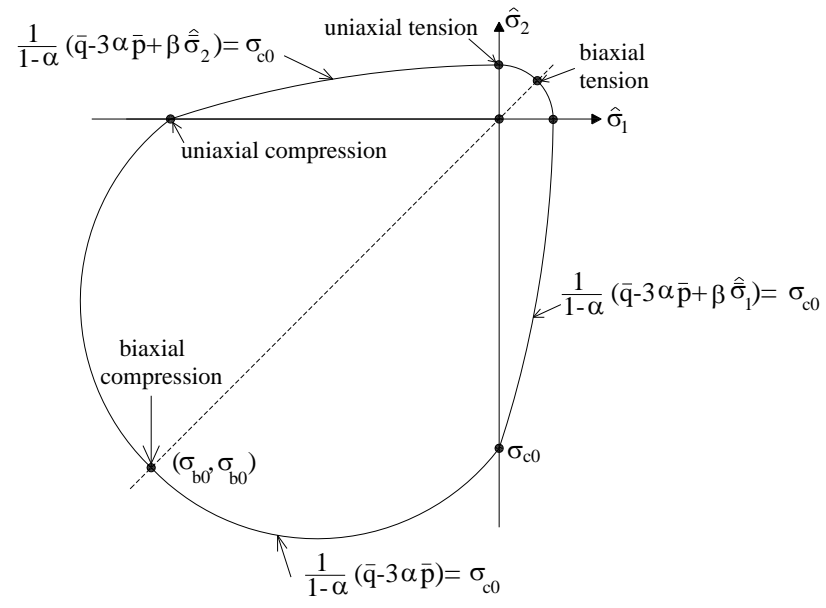

Fig. 7 - Yield surface under biaxial stress used in the concrete damage plasticity model. 


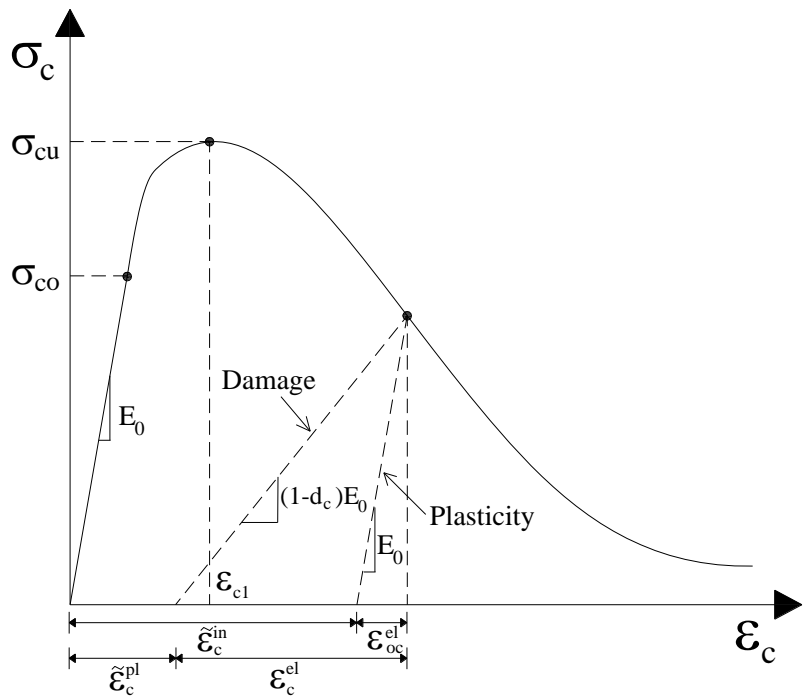

Fig. 8 - Definition of inelastic compressive strain in the CDP model. 


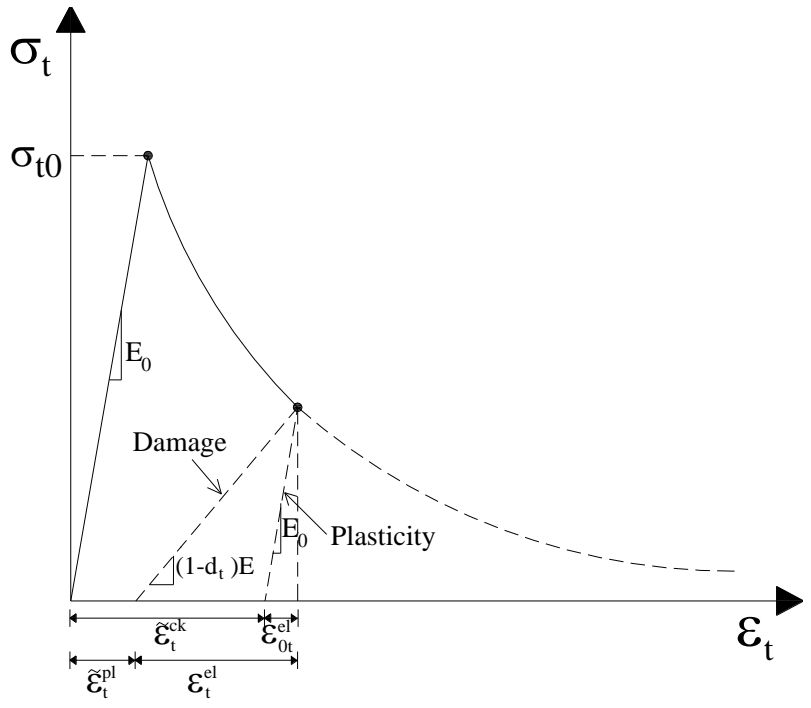

Fig. 9 - Strain definition after cracking-tension stiffening. 


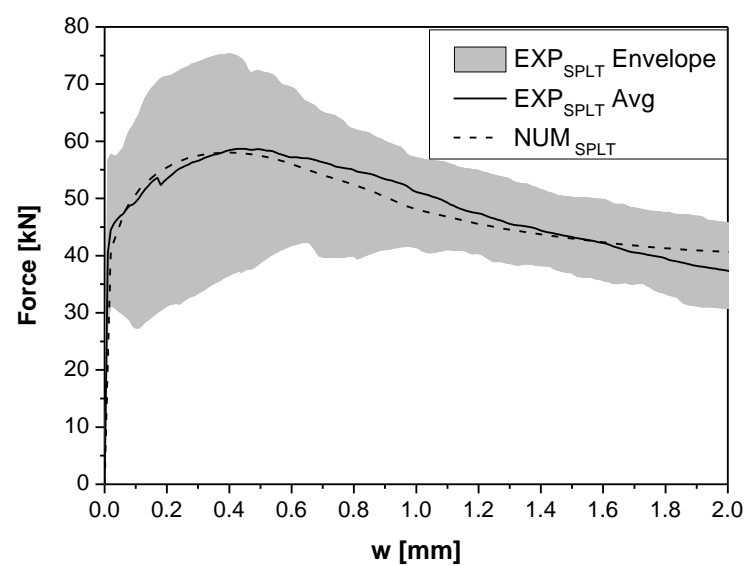

(a)

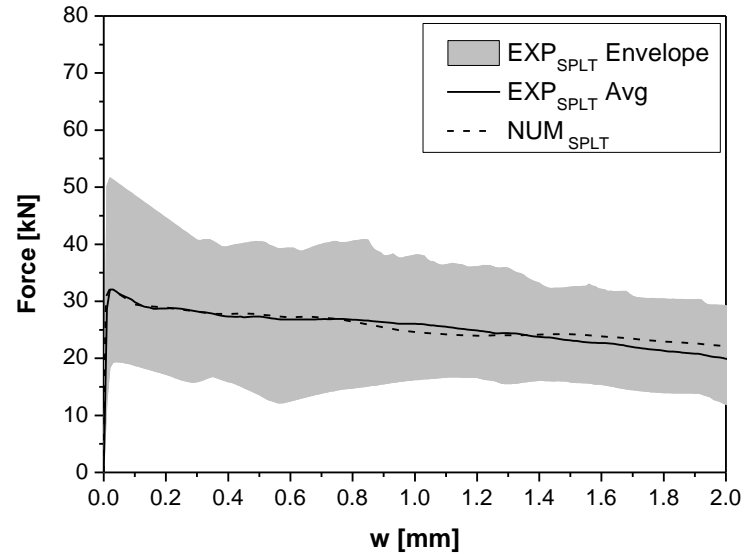

(b)

Fig. 10 - Experimental and numerical force - crack width relationship, $F$ - $w$, for: (a) $\theta=0^{\circ}$ and (b) $\theta=90^{\circ}$. 


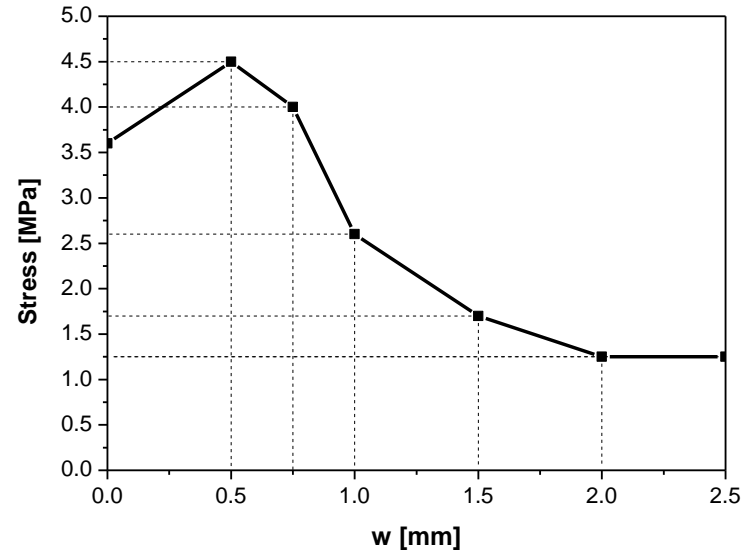

(a)

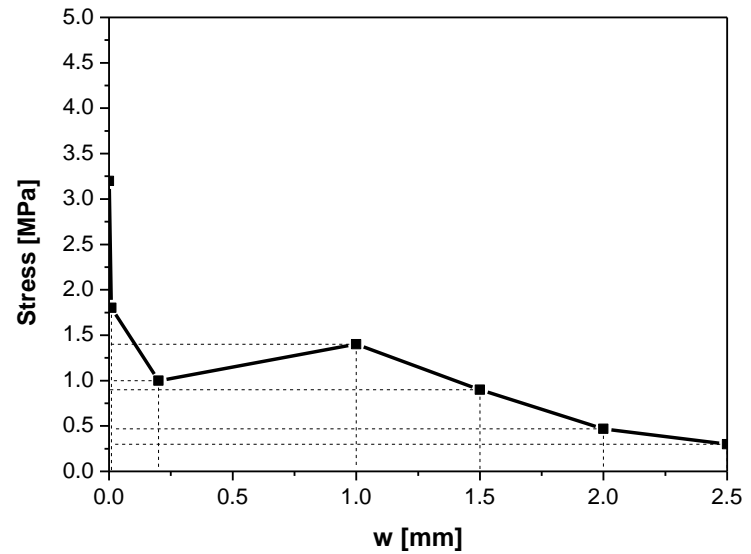

(b)

Fig. 11 - Numerical uniaxial stress - crack width relationship, $\sigma-w$, obtained from inverse analysis for: (a) $\theta=0^{\circ}$ and (b) $\theta=90^{\circ}$. 


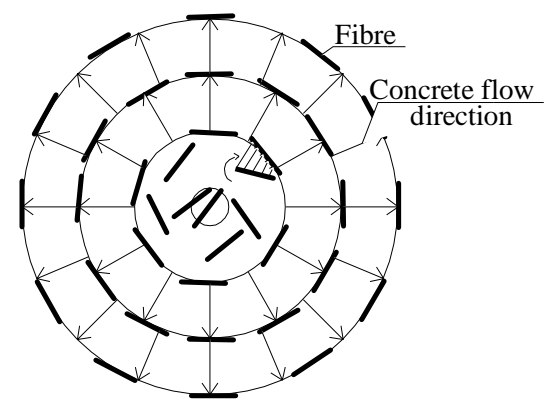

Fig. 12 - Explanation for fibre alignment in flowing concrete of a panel casting from the centre. 


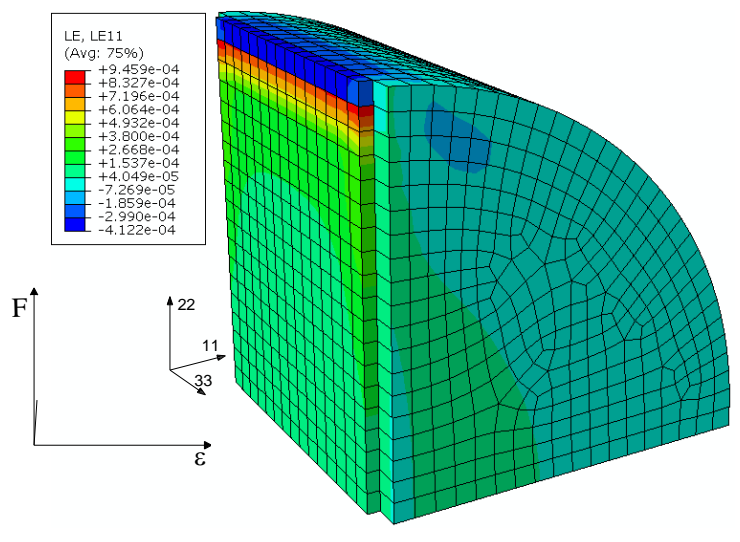

(a)

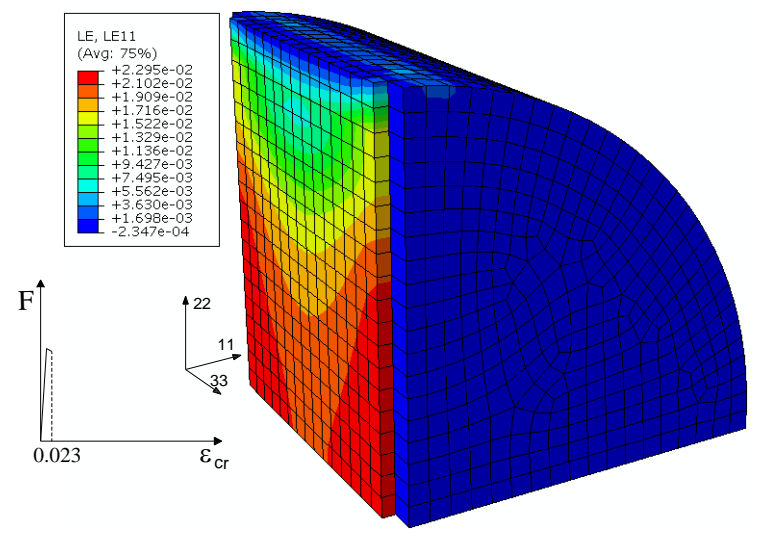

(c)

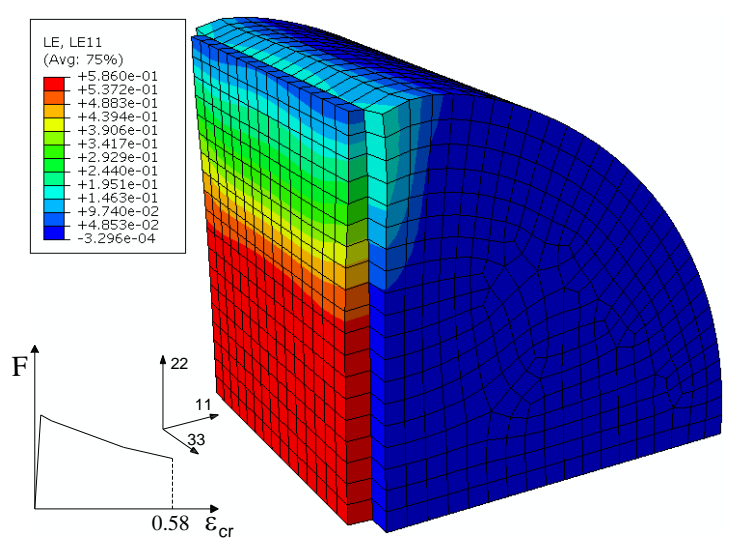

(e)

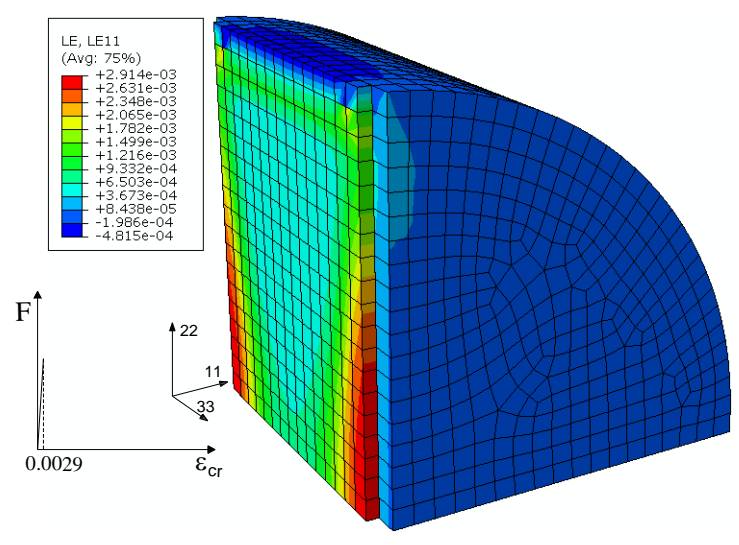

(b)

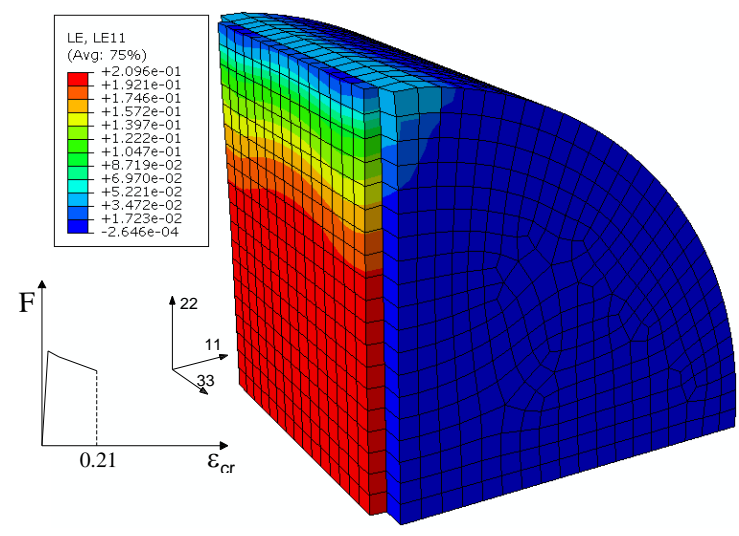

(d)

Fig. 13 - Strain distribution in numerical model. 

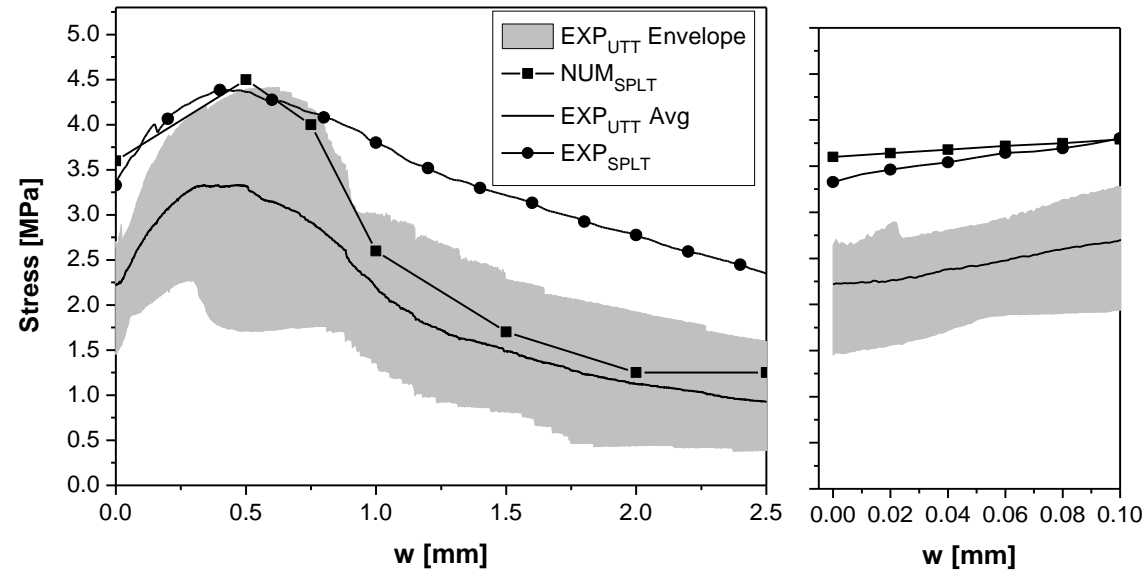

Fig. 14 - Comparison of the uniaxial stress - crack width relationship, $\sigma-w$, for $\theta=0^{\circ}$. 


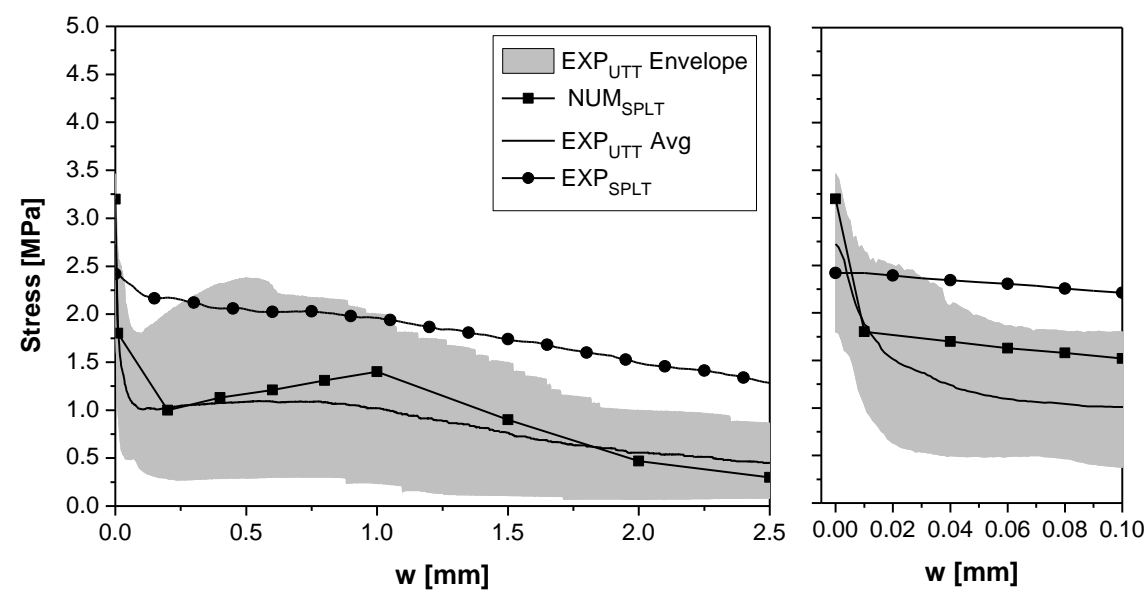

Fig. 15 - Comparison of the stress - crack width relationship, $\sigma-w$, for $\theta=90^{\circ}$. 


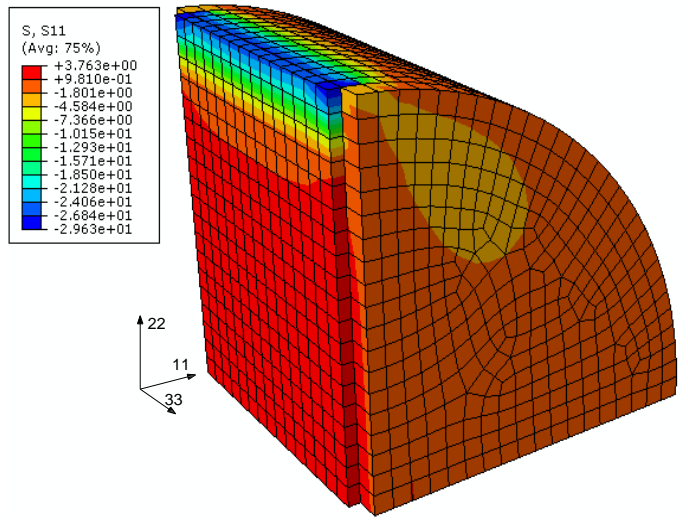

(a)
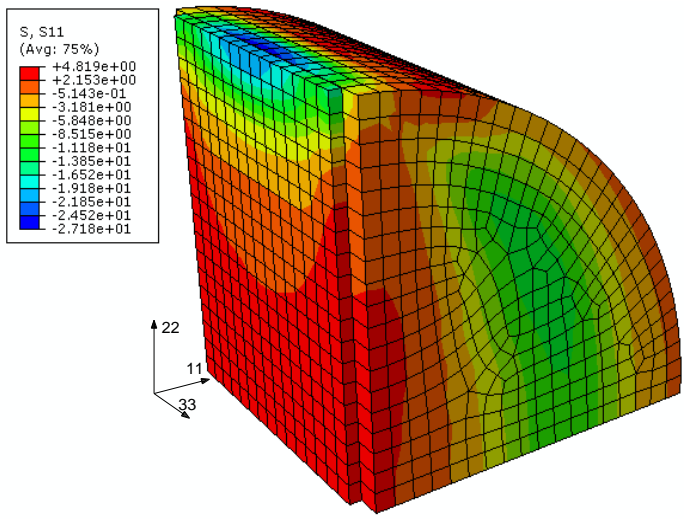

(c)

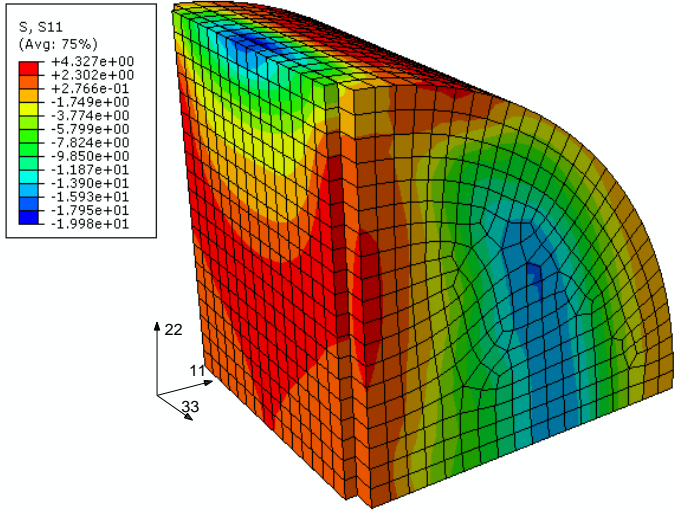

(e)

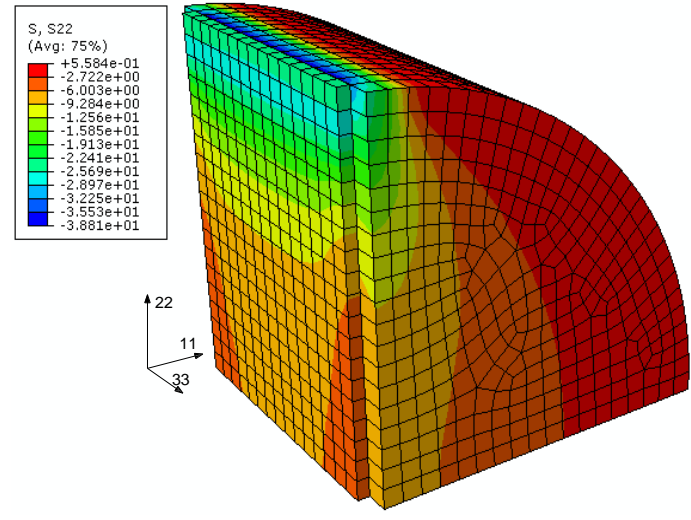

(b)

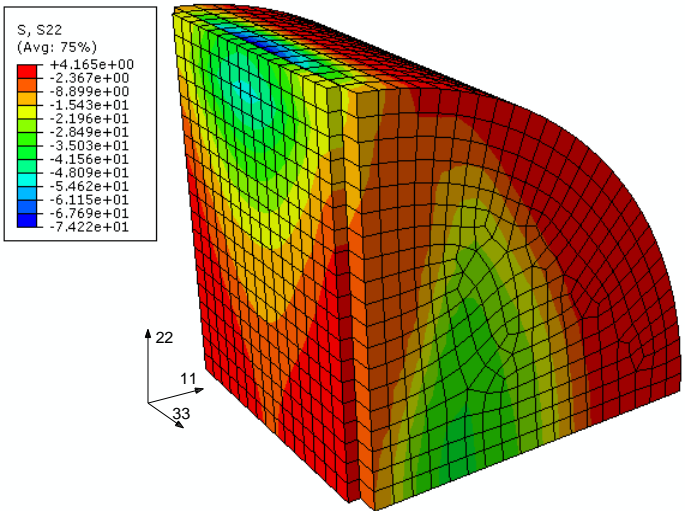

(d)

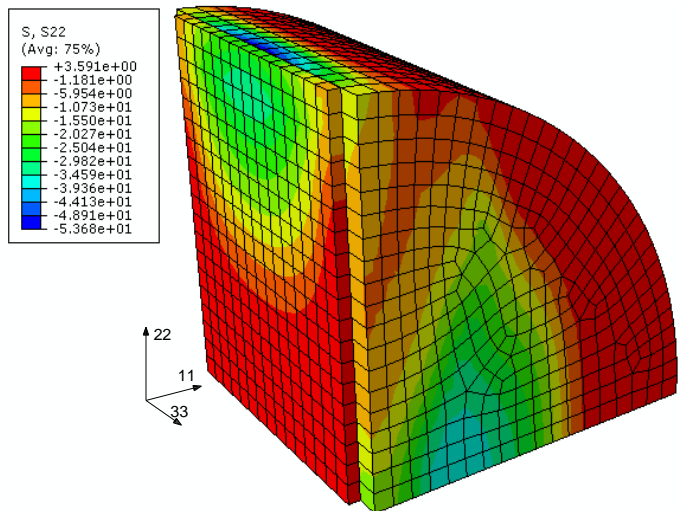

(f)

Fig. 16 - Stress distribution in numerical modeling of $\theta=0^{\circ}$ specimen: (a) horizontal direction at the time of the crack initiation, (b) vertical direction at the time of the crack initiation, (c) horizontal direction and $w=0.5 \mathrm{~mm}$,

(d) vertical direction and $w=0.5 \mathrm{~mm}$, (e) horizontal direction and $w=1 \mathrm{~mm}$, (f) vertical direction and $w=1$ $\mathrm{mm}$. 


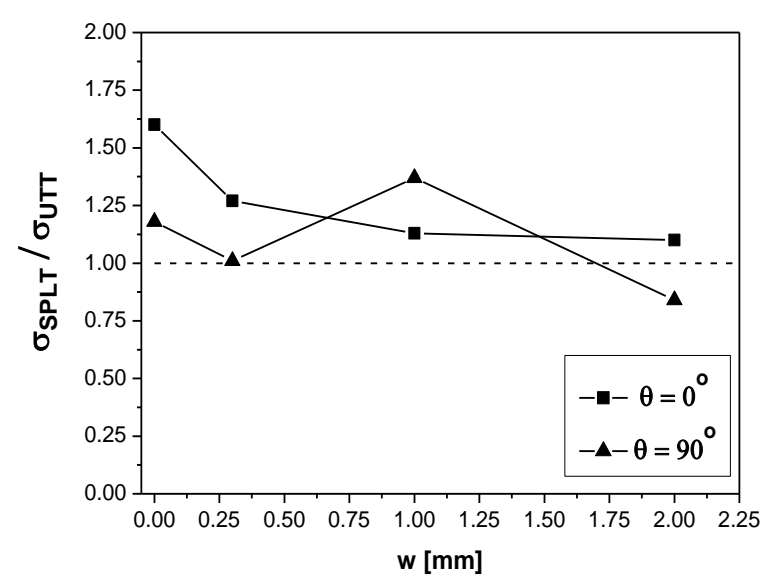

(a)

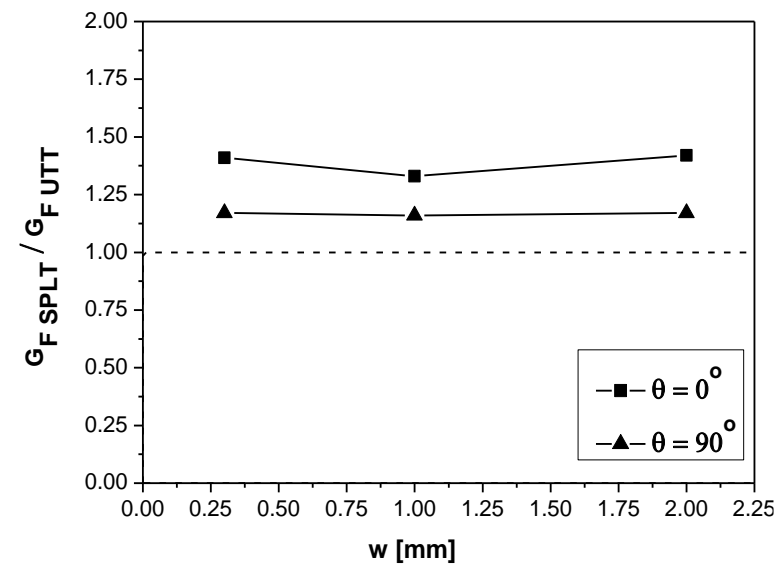

(b)

Fig. 17 - Numerical splitting tensile post-cracking parameters versus experimental uniaxial tensile post-cracking parameters: (a) Residual stress and (b) Fracture energy. 
Table 1 - Mix proportions of steel fibre reinforced self-compacting concrete per $\mathrm{m}^{3}$.

\begin{tabular}{|c|c|c|c|c|c|c|c|c|}
\hline $\begin{array}{c}\text { Cement } \\
{[\mathrm{kg}]}\end{array}$ & $\begin{array}{c}\text { Water } \\
{[\mathrm{kg}]}\end{array}$ & $\begin{array}{c}\text { W/C } \\
{[-]}\end{array}$ & $\begin{array}{c}\text { SP } \\
{[\mathrm{kg}]}\end{array}$ & $\begin{array}{c}\text { Filler } \\
{[\mathrm{kg}]}\end{array}$ & $\begin{array}{c}\text { Fine sand } \\
{[\mathrm{kg}]}\end{array}$ & $\begin{array}{c}\text { Coarse sand } \\
{[\mathrm{kg}]}\end{array}$ & $\begin{array}{c}\text { Coarse aggregate } \\
{[\mathrm{kg}]}\end{array}$ & $\begin{array}{c}\text { Fibre } \\
{[\mathrm{kg}]}\end{array}$ \\
\hline 413 & 140 & 0.34 & 7.83 & 353 & 237 & 710 & 590 & 60 \\
\hline
\end{tabular}


Table 2 - The constitutive parameters of CDP model.

\begin{tabular}{|c|c|}
\hline Dilatation angle [degrees] & 40 \\
\hline Eccentricity, $e[-]$ & 0.1 \\
\hline$\sigma_{b o} / \sigma_{c o}[-]$ & 1.16 \\
\hline$K_{c}[-]$ & 0.667 \\
\hline
\end{tabular}


Table 3 - Mechanical properties adopted in the numerical simulations.

\begin{tabular}{|c|c|}
\hline Density, $\rho$ & $2.4 \times 10^{6} \mathrm{~N} / \mathrm{mm}^{3}$ \\
\hline Poisson ratio, v & 0.2 \\
\hline Initial young modulus, $E_{c i}$ & $34.15 \mathrm{~N} / \mathrm{mm}^{2}$ \\
\hline Compressive strength, $f_{c m}$ & $47.77 \mathrm{~N} / \mathrm{mm}^{2}$ \\
\hline Tensile strength & Inverse analysis \\
\hline Post-cracking parameters & Inverse analysis \\
\hline
\end{tabular}


Table 4 - Comparison of the FE analysis and experimental results.

\begin{tabular}{|c|c|c|c|c|c|c|c|}
\hline & & $\begin{array}{c}F_{c r} \\
{[\mathrm{kN}]}\end{array}$ & $\begin{array}{l}F_{\text {peak }} \\
{[\mathrm{kN}]}\end{array}$ & $\begin{array}{c}F_{0.3} \\
{[\mathrm{kN}]}\end{array}$ & $\begin{array}{c}F_{1} \\
{[\mathrm{kN}]}\end{array}$ & $\begin{array}{c}F_{2} \\
{[\mathrm{kN}]}\end{array}$ & $\begin{array}{l}\text { err } \\
{[\%]}\end{array}$ \\
\hline \multirow{2}{*}{$\begin{array}{l}\theta=0^{\circ} \\
\left(F_{\|}\right)^{*}\end{array}$} & $\mathrm{NUM}_{\text {SPLT }}$ & 40 & 58.67 & 57.53 & 48.03 & 40.51 & \multirow{2}{*}{3.92} \\
\hline & $\mathrm{EXP}_{\mathrm{SPLT}}$ & 40.5 & 58.04 & 56.58 & 51.13 & 37.36 & \\
\hline \multirow{2}{*}{$\begin{array}{c}\theta=90^{\circ} \\
\left(F_{\perp}\right)^{*}\end{array}$} & $\mathrm{NUM}_{\text {SPLT }}$ & 27.12 & 32.25 & 28.32 & 24.62 & 22.13 & \multirow{2}{*}{3.82} \\
\hline & $\mathrm{EXP}_{\mathrm{SPLT}}$ & 28.02 & 32.08 & 28.20 & 26.04 & 19.93 & \\
\hline
\end{tabular}

* $\|$ and $\perp$ - notch direction parallel $\left(\theta=0^{\circ}\right)$ and perpendicular $\left(\theta=90^{\circ}\right)$ to the concrete flow direction, respectively. 
Table 5 - Residual stress and toughness parameters obtained from different analysis.

\begin{tabular}{|c|c|c|c|c|c|c|c|}
\hline Series & Parameter & $\begin{array}{c}\sigma_{\text {peak }} \\
{[\mathrm{MPa}]}\end{array}$ & $\begin{array}{c}\sigma_{0.3} \\
{[\mathrm{MPa}]}\end{array}$ & $\begin{array}{c}\sigma_{1} \\
{[\mathrm{MPa}]}\end{array}$ & $\begin{array}{c}\sigma_{2} \\
{[\mathrm{MPa}]}\end{array}$ & $\begin{array}{c}G_{F 1} \\
{[\mathrm{~N} / \mathrm{mm}]}\end{array}$ & $\begin{array}{c}G_{F 2} \\
{[\mathrm{~N} / \mathrm{mm}]}\end{array}$ \\
\hline \multirow{3}{*}{$\begin{array}{c}\theta=0^{\circ} \\
\left(\sigma_{\|}\right)\end{array}$} & NUM $_{\text {SPLT }}$ & 4.50 & 4.10 & 2.60 & 1.25 & 3.91 & 6.35 \\
\hline & $\mathrm{EXP}_{\text {SPLT }}$ & 4.39 & 4.23 & 3.82 & 2.79 & 4.07 & 7.32 \\
\hline & EXP $_{\text {UtT }}$ & 3.33 & 3.24 & 2.30 & 1.14 & 2.94 & 4.47 \\
\hline \multirow{3}{*}{$\begin{array}{c}\theta=90^{\circ} \\
\left(\sigma_{\perp}\right)\end{array}$} & NUM $_{\text {SPLT }}$ & 3.20 & 1.06 & 1.40 & 0.47 & 1.26 & 2.18 \\
\hline & $\mathrm{EXP}_{\text {SPLT }}$ & 2.47 & 2.13 & 1.96 & 1.50 & 2.08 & 3.83 \\
\hline & EXP $_{\text {UtT }}$ & 2.72 & 1.05 & 1.02 & 0.56 & 1.09 & 1.86 \\
\hline
\end{tabular}

